\title{
Altın Oran (Leonardo Fibonacci) Dikimi ve Mikoriza Uygulamasının Domatesin Verim ve Kalite Özellikleri Üzerine Etkileri
}

\author{
Mustafa Emre Özeren ${ }^{2} \quad$ Seçkin Kaya $^{1} \quad$ Cafer Türkmen $^{2 *}$
}

${ }^{1}$ Çanakkale Onsekiz Mart Üniversitesi Ziraat Fakültesi Bahçe Bitkileri Bölümü, 17020 Çanakkale, Türkiye.

${ }^{2}$ Çanakkale Onsekiz Mart Üniversitesi Ziraat Fakültesi Toprak Bilimi ve Bitki Besleme Bölümü, 17020 Çanakkale, Türkiye.

*Sorumlu yazar: turkmen@comu.edu.tr

Geliş Tarihi: 21.06.2019

Kabul Tarihi: 23.10.2019

\section{$\ddot{O} z$}

Mikoriza'nın domateste beslenme üzerine olan etkileri pek çok kez incelenmişse de, meyve kalitesi üzerine olan etkilerinin belirlenmesi için halen yeni çalışmalara gerek duyulmaktadır. Diğer yandan, altın oran ölçeğine göre yapılan fide dikiminin domateste verim ve kaliteye olası fayda ve zararları konusunda bir çalışmaya rastlanmamıştır. Bu çalışma, tarla koşullarında iki farklı dikim deseninin ve domates fidelerine inoküle edilen Arbusküler Mikoriza (AM)'nın meyve kalitesi üzerine olan etkilerinin belirlenmesi amacıyla yürütülmüştür. Domates fideleri Standart Dikim (SD) şekli ve bitkilerin sıra üzeri ve sıra arası mesafelere Altın Oran (AO)'ın uygulandığı dikim şeklinde planlanan parsellere; Mikorizalı $\left(\mathrm{M}^{+}\right)$ve Mikorizasız $\left(\mathrm{M}^{-}\right)$olarak ayrı ayrı dikilmiştir. Elde edilen sonuçlara göre, tek meyve ağırlıkları dikim şeklinden istatistiki olarak etkilenmiştir $(p \leq 0,05)$. Standart dikim şeklinden elde edilen meyvelerin ağırlıkları AO dikim şekline göre daha yüksek değerler verirken, mikoriza faktörünün meyve ağırlıkları üzerine etkisi istatistiki olarak önemsiz bulunmuştur. Meyve ağırlıklarındaki değişim meyve boyutlarında da görülmüştür $(p \leq 0,05)$. Standart dikim şeklindeki meyvelerin boyu ve eni AO dikim şekline göre daha yüksek sonuçlar verirken, meyve boyutlarını mikoriza uygulaması istatistiki olarak etkilememiştir. Meyve kabuk rengi hem dikim şeklinden hem de mikoriza uygulamalarından istatistiki olarak etkilenmemiştir. Suda Çözünebilir Kuru Madde miktarı yüzdesi (\%SÇKM) ve Titre Edilebilir Toplam Asitlik yüzdesi (\%TETA) özelliklerine, dikim şekli ve mikoriza uygulamalarının istatistiki olarak etkisi olmamıştır. Vitamin C bakımından ise mikoriza uygulamasının her iki ekim şeklinde de bir etkisi görülmemişken SD şekliyle elde edilen ürünlerde $\mathrm{C}$ vitamini daha fazla ölçülmüştür $(p \leq 0,05)$. Sonuç olarak mikoriza uygulamaları her iki dikim şeklinde domates verimi ve kalitesine etki etmemiş; SD şekline göre AO dikim şekli de domatesin verim ve kalitesi yönünden beklenen başarıyı gösterememiştir. Altın oran dikim şeklinde domates bitkileri arasındaki mesafelerin, özellikle küçük parsellerde yetersiz olabileceği sonucuna varılmıştır.

Anahtar Kelimeler: Dikim şekli, Altın oran, Mikoriza, Domates, Kalite

\section{The Effects of Golden Ratio (Leonardo Fibonacci) Planting and Mycorrhiza on Basic Quality Traits of Tomato}

\section{Abstract}

However Mycorrhiza and its effects on the nutrition of tomatoes have been examined many times, further studies are still needed to determine the effects on fruit quality. On the other hand, there is no study on the possible benefits and detriments of seedling planting according to the golden ratio scale on yield and quality. This study was conducted to determine the effects of two different planting designs and Arbuscular Mycorrhiza (AM) inoculated to tomato seedlings on fruit quality, in field conditions. Tomato seedlings were planted to the parcels in the form of standard design (SD) and planting in which the Golden Ratio (GR) is applied to row spaces and intra row distances of the plants with Mycorrhizal $\left(\mathrm{M}^{+}\right)$and without Mycorrizhal $\left(\mathrm{M}^{-}\right)$, separately. According to the results obtained fruit weights were statistically affected by planting design $(p \leq 0,05)$. The weight of fruits obtained from the standard planting design gave higher values than GR planting, while the effect of a mycorrhizal factor on fruit weights was not statistically significant. The variation in fruit weights was also observed in fruit sizes $(p \leq 0,05)$. The length and width of the fruits of standard planting were higher than those of GR planting, while the mycorrhiza treatments did not have a statistically significant effect on fruit sizes. Fruit peel color was not affected statistically from both planting design and mycorrhiza treatments. Neither the planting design nor the mycorrhizal treatments had a statistical effect on Soluble Solid Content (SSC\%) and titrable acidity (TA\%). While the amount of vitamin $\mathrm{C}$ was not affected by mycorrhizal treatments and both planting designs, vitamin $\mathrm{C}$ was measured more in the fruits harvested from SD designed parcels. As a result, mycorrhizal treatments did not affect the yield and quality of tomatoes in both planting designs; also both SD and GR planting design did not show the expected success in terms of yield and fruit quality. 
Key words: Planting design, Golden ratio, Mycorrhiza, Tomato, Quality

\section{Giriş}

Domates (Lycopersicon lycopersicum L.) 2017 y1lında, yaklaşık 182 milyon tonluk üretimiyle dünyada en fazla üretilen sebzelerden biridir (Anonim, 2018). Ülkemizde de FAO verilerine göre 187.070 ha alanda 1.275.000 ton domates üretimi yapılmıştır (Anonim, 2017a). Çanakkale ilimiz domates üretiminde ülkemizin önde gelen illerinden biridir. Çanakkale'de 2017 yılında 387.911 tonu sofralık, 212.803 tonu da salçalık olmak üzere toplam 600.714 ton domates üretilmiştir (Anonim 2017b). Hem taze tüketim hem de gıda sanayisinde hammadde olması nedeniyle domates üretim miktarı her geçen yıl artmaktadır (Hanareh ve ark., 2015). Ekonomik öneminin yanı sıra, yetiştiriciliğinin kısa periyotta tamamlanması, ekolojik koşullara adaptasyonunun yüksek olması, homozigotiye yatkın olması gibi birçok avantajından dolayı, bilimsel olarak da üzerinde en çok araştırma yapılan ürünlerden biridir (Foolad, 2007). Domates aynı zamanda insan sağlığına olan yararları bakımından da oldukça fazla üzerinde durulan bir sebze türüdür. İçerdiği vitaminler, mineraller ve organik asitler gibi birçok maddenin insan sağlı̆ğ açısından yararları kanıtlanmıştır. Tüketimine bağlı olarak kanser ve kardiyovasküler hastalıklar riskini azalttığına ilişkin epidemiyolojik bulguları nedeniyle biyofonksiyonel (antioksidan, biyoaktif) yiyecekler statüsünde olduğu bildirilmektedir (Giovannetti ve ark., 2012). Domatese kırmızı rengini de veren likopenin taze domateslerde ve işlenmiş domates ürünlerinde bulunan ana antioksidanlardan biri olduğu ve diğer karotenlerin (beta-karoten gibi), $\mathrm{C}$ vitamini, $\mathrm{E}$ vitamini ve çeşitli fenolik bileşiklerin de antioksidan özelliklere sahip sağlığı teşvik edici faktörler olduğu düşünülmektedir (Dumas ve ark., 2003).

Çanakkale ilinde domates hem sofralık hem de salçalık olarak üretilmekte ve üretim şekline göre dikim aralıkları değişmektedir. Ancak genel olarak sofralık üretimlerde dikim 1,40 m x 0,66 m sıra arası ve sıra üzeri mesafelerde yapılmaktadır. Bununla birlikte domates dikim mesafeleri, domates değerlendirme şekli, çeşit özellikleri gibi çeşitli nedenler ile değişiklik gösterebilmektedir (Vural ve ark., 2000; Günay, 2005). Yukarıda da belirtildiği gibi dikim mesafe aralıklarından bakım işlemlerine kadar birçok kültürel işlem verim ve kaliteyi etkilemektedir. Son yıllarda ilgi odağı olan ve bitki gelişimine olumlu etkisi olduğu düşünülen mikroorganizmaların tarımda kullanımı da artış göstermektedir. Bunlardan biri de mikorizadır. Mikoriza bitki kökleri ile mantar hifleri arasında oluşan simbiyotik bir yaşam şeklidir. "Mikoriza" teriminin yunanca kaynaklı olduğu, kök mantarı anlamına geldiği ve myco: mantar ve rhiza: kök kelimelerinin birleşmesinden oluşan bir kelime olduğu bildirilmektedir (Ortaş, 1997). Mikorizalar aynı zamanda sağladığı çeşitli yararlardan dolayı tarımda çok bilinen ve kullanılan faydalı mikroorganizmalardandır. Genel olarak bitki ve mantar oluşan ortak yaşamdan karşılıklı fayda sağlamaktadırlar (Alexopouluos, 1962). Mikoriza mantarları enfeksiyon seçiciliği ve bitki kökü içindeki morfolojik yap1 yönünden "ekto" ve "endo" mikoriza olarak ikiye ayrılırlar. Ekto mikorizalarda fungus hifleri bitkinin kök kabuğu hücreleri arasında bir ağ oluşturur ve az miktarda korteks hücrelerinin arasına girer (Uluer ve Karabulut, 1999). Endomikorizalar ise dünya üzerinde en yaygın kök-mantar birlikteliği gösteren mantarlardır. Bunlar, Vesiküler Arbüsküler Mikoriza (VAM) olarak da adlandırılmaktadırlar (Wang ve Qiu, 2006). VAM ekto mikorizadan farklı olarak kök morfolojisinde de değişiklik yaratmamaktadır. Bu tip mantarlar kök hücreleri içinde gelişerek besleyici köklerin etrafında bir hif ağı oluştururlar (Kara ve Tilki, 2001).

Mikoriza mantarlarının inokule olduğu bitkiye birçok yönden fayda sağladığı çeşitli araştırıcılar tarafından bildirilmektedir. Mikoriza mantarları özellikle az hareketli mineral elementlerin bitki tarafından alımını artırmaktadır. Bunların başında fosfor, çinko ve bakır gelmektedir (Ortaş ve ark., 2011). Mikoriza mantarlarının bitki büyümesine olumlu etkide bulunduğu, su ve bitki besin elementlerinin topraktan alımını kolaylaştırdığı, fotosentez hızını artırdığı, tuzluluk, kuraklık gibi stres kaynaklarına karşı bitki dayanıklılığını artırdığını aynı araştırmacı bir başka çalışmasında belirtmiş̧ir (Ortaş, 2010). Ayrıca yapılan çalışmalar mikoriza mantarlarının bazı zararlılar ve toprak kökenli patojenlere karşı da bitkilerin dayanımını artırdığını bildirmişlerdir (Al-Karaki, 2006). Bitkiler için sayılan bütün bu faydaların temel nedeninin bitkinin fosfor bakımından artan beslenmesi olduğu öne sürülmektedir (Plenchette ve ark., 2005).

Doğada altın oran sıklıkla rastlanmakta ve Fibonacci sayılarına göre büyüme gelişme gösteren salyangoz, koçboynuzu, fil hortumu, vb. birçok canlıdan söz edilmektedir (Murchie, 1999). Benzer şekilde altın oranlı doğal tasarımların biyosferde birçok canlıda görüldüğü, hidrosferde ve atmosferde 
akışkan hareketlerini kolaylaştıran büyük tasarımın ayrılmaz bir parçası olduğu belirtilmektedir (Bejan, 2009). Altın oran $\mathrm{AB} / \mathrm{CB}=\mathrm{CB} / \mathrm{AC}$ ya da $\Phi \mathrm{x} / \mathrm{x}=\mathrm{x} / \mathrm{x}(\Phi-1)$ denkleminin aç1lımından $\Phi 2-\Phi-1=0$ denklemi çözüldüğünde, $\Phi=(1+\sqrt{5}) / 2=1,618033 \ldots$ olarak ulaşılan sayıdır. Bu sonuçtan da şöyle bir tanım çıkarmak mümkündür; altın oran, 1 sayısına eklendiğinde kendi karesine eşit olan iki sayıdan biridir; bunlardan ilki 1,618033 ... olarak devam eden ondalık sayıdır. Denklemin ikinci kökü ise $0,618033 \ldots$ olarak devam eden ondalık sayıdır. Bir başka deyişle altın oran kendisinden "1" çıkarıldığında kendi ters değerine eşit olan tek sayıdır. Altın oran ile ilgili çalışmaların en önemlisi İtalyan matematikçi Filius Bonacci (Fibonacci)'nin bulduğu sayılar serisidir. Dizideki sayılardan her biri, kendisinden önce gelen iki sayının toplamından oluşmaktadır ve dizideki ardışık sayıların oranı birbirine çok yakındır ve 13. sayıdan sonra sabitlenerek altın oranı vermektedir. Fibonacci Sayıları: 0, $1,1,2,3,5,8,13,21,34,55,89,144,233,377,610,987,1597,2584, \ldots$ sşeklinde devam etmektedir (Selçuk ve ark., 2009).

Prokopakis ve ark., (2013) simetri kelimesinin etimolojisine ile belirli güzellik örnekleri ve teorilerine dayanarak, altın oran olarak bilinen $\Phi$-değerinin simetrik formları karakterize edebileceği sonucuna vardıklarını; bu nedenle, bu oranın yüz estetiğinde kullanılmasını önerdiklerini belirtmişlerdir. Rönesans mimarları, sanatçıları ve tasarımcıları da bu ilginç konu üzerinde çalışmışlar; seçkin heykel, resim ve mimari eserlerinde altın oranları belgeleyerek kullanmışlardır (Akhtaruzzaman ve Shafie, 2011). Geçmişte bir çok dikim mesafesi denemesi yürütülmüş ve dikim yoğunluğunun verim ve kaliteyi etkilediği çeşitli araştırıcılar tarafından bildirilmiştir (Papadopoulos ve Ormrod, 1991; Agele ve ark., 1999; Saka, 2012; Yıldırım ve Bahar, 2017). Ancak yapılan bütün çalışmalarda dikim sistemi genellikle sıraya dikim şeklinde yapılmış ve sıra üzeri veya sıra arası mesafelerin değişmesi ile metrekareye düşen bitki sayıları değişmiştir.

$\mathrm{Bu}$ çalışmada ise domates bitkisi fideleri için altın oran ilk olarak bir dikim şekli olarak seçilmiş ve standart dikim şekliyle karşılaştırılmıştır. Yanısıra tarla şartlarında her iki dikim şeklindeki fidelere mikoriza var/yok uygulaması yapılmış ve elde edilen ürünlerde meyve verimi ve temel kalite parametreleri belirlenmiştir. Çanakkale Dardanos tarla şartlarında planlanarak yürütülen bu araştırmayla domates bitkisi üzerine altın oran ve normal fide dikim şekli ile mikoriza uygulamalarının ayrı ayrı ve birlikte etkilerinin belirlenme şansı ilk olarak elde edilmiştir.

\section{Materyal ve Yöntem}

Deneme alanı $40^{\circ} .12^{1} \mathrm{~N}, 28^{\circ} .38^{1}$ E koordinatlarında, Anadolu yarımadasının kuzey batısında ve Trakya'nın güney batısında bulunmaktadır. Bu bölge genellikle Akdeniz ve Karadeniz iklim kuşaklarının geçiş bölgesi özelliklerini taşımaktadır. Denemeler mikorizalı ve mikorizasız parsellerde altın oran ve standart dikimlerin yapılması şeklinde bölünmüş parseller deneme desenine göre 3 tekerrürlü olarak yürütülmüştür.

Dikim şekilleri standart dikim parsellerinde, domates fideleri 66,6 x $100 \mathrm{~cm}$ sıra üzeri ve sıra arası mesafelerde dikilmiştir. Altın oran dikim şeklinde ise bitkiler 1,618033 .. oranına bağlı olarak artan aralıklarda helezonik olarak "Blender" açık erişim programı (Anonim, 2016) yardımıyla üç boyutlu modelleme ve canlandırma uygulaması kullanarak bez branda üzerine işaretlenen noktaların daha sonra araziye aplikasyonu şeklinde yapılmıştır (Şekil 1).

Altın orana göre dikilmiş deneme parsellerinde birim alana dikilen domatesler, SD yapılmış domateslere göre daha fazla sayıda olmuştur. Standart dikimlerde bu sayı parsel başına 12 adet iken, altın orana göre birim alana dikilen domates sayısı 18 adet olmuştur. Bu nedenle parsel başına verim değerleri dikkate alınmamıştır. Parsel boyutları SD şeklinde $2 \times 2 \mathrm{~m}$ boyutlarında olmuş AO dikim şeklinde de alan olarak eşitlenmiştir. 


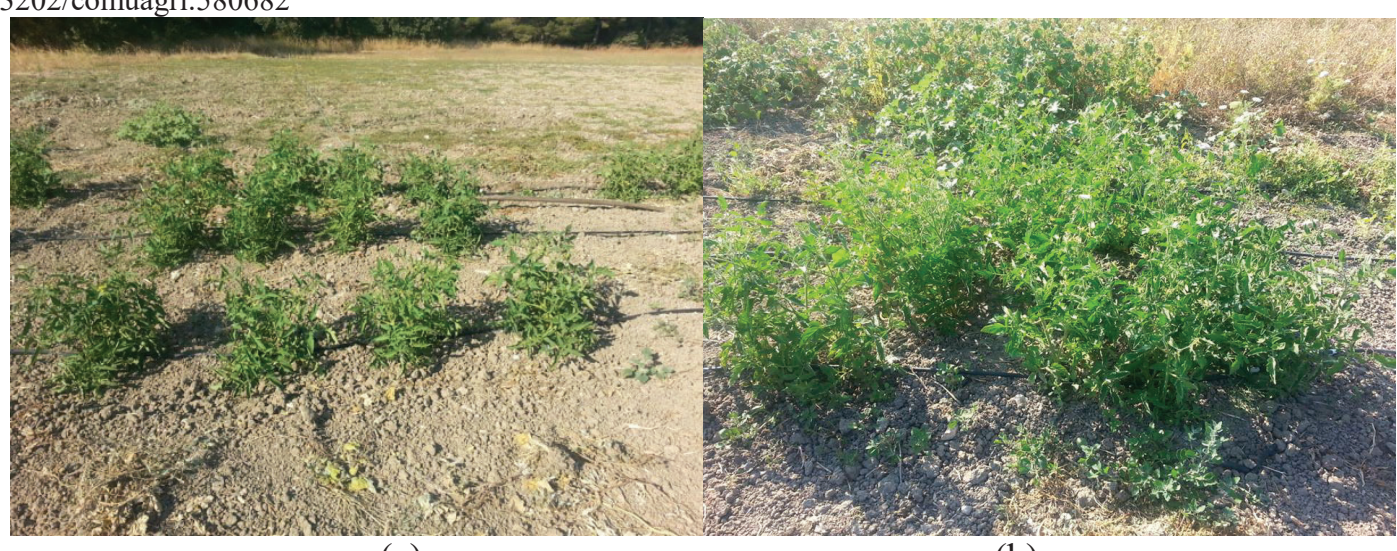

(a)

(b)

Şekil 1. Standart düzende (a) ve altın oranda (b) dikilmiş domates fideleri (orijinal resim).

Denemelerde "Sakata Tohum" tarafından üretilen "Troy $F_{1}$ " domates çeşidi kullanılmıştır. Genel olarak çeşit kataloğunda 200-250 g meyve ağırlığına sahip, koyu kırmızı renkte, basık yuvarlak meyve şekilli olarak tanımlanmıştır. Çanakkale yöresinde en çok yetiştirilen çeşitlerden biridir ve ortalama verimi 8-10 ton $\mathrm{da}^{-1}$ civarındadır. Dikim yapılacak alanda toprak hazırlığı, dikim, bakım işlemleri Günay (2005) ve Vural ve ark. (2000)'na göre yapılmıştır.

Mikoriza uygulamasında "Bioglobal AŞ" tarafından ülkemizde satışa sunulan karışık kültür mikoriza ürünü olan Endo Roots Soluble (ERS)'nin (Çizelge 1) suda çözünür toz formülasyonu kullanılmıştır. Mikoriza sporları önceden temiz bir kapta $\mathrm{pH}>7$ klor içermeyen tuzsuz temiz bir su ile gölgede karıştırılarak bir gece bekletilmiştir. Ertesi gün dikilecek fideler, viyollerden alınarak köklerini gölgede en az 60 saniye mikoriza sporu içeren bu kaba bandırma şeklinde dikim öncesi enfeksiyona tabi tutulmuştur.

Çizelge 1. Denemede kullanılan mikoriza kültürü içerik ve miktarları*

\begin{tabular}{|c|c|}
\hline ERS içeriğindeki kültü̈ler & Kültür içindeki miktarları (\%) \\
\hline Glomus intraradices & 21 \\
\hline Glomus aggregatum & 20 \\
\hline Glomus mosseage & 20 \\
\hline Glomus clarum & 1 \\
\hline Glomus monosporus & 1 \\
\hline Glomus deserticola & 1 \\
\hline Glomus brasilianum & 1 \\
\hline Glomus etunicatum & 1 \\
\hline Gigaspora margarita & 1 \\
\hline
\end{tabular}

*: Garanti edilen canlı kültür ağırlığı toplam ağırlı̆̆ı \% 23,5 ( $\left.\mathrm{g} \mathrm{g}^{-1}\right)^{\prime}$ i kadardır.

Çalışma temel özellikleri bilinen ÇOMÜ Ziraat Fakültesi Dardanos Araştırma Uygulama Çiftliği topraklarında tarla şartlarında tek yıllık (2016) olarak yürütülmüştür. Çalışma alanının temel toprak özellikleri; toprak bünyesi, killi-tın (CL), tuz seviyesi, tuzsuz $\left(0,39-0,66 \mathrm{dS} \mathrm{m}^{-1}\right)$ seviyelerinde, organik maddesi, az $(\% 1,5-2,0)$, kireç içeriği, orta $(\% 11,86-14,28)$ seviyede, $\mathrm{pH}$ değeri nötr $(7,02-$ 7,09) civarındadır (Parlak ve ark., 2017). Dardanos çiftliğinde deneme yürütülen seriye ait bölge toprakları Amerikan sinıflama sistemine göre "Typic Haploxerert"ler veya FAO/UNESCO sinıflamasına göre "Eutric Vertisol"ler olarak bildirilmiştir (Özcan ve ark., 2004). Bölge iklimi; Akdeniz iklimi ile nemli Karadeniz iklimi arasında geçiş iklimi kuşağındadır, "Yarı Nemli Marmara Geçiş İklimi" şeklinde adlandırılır (Türkeş ve ark., 2011). Yı1lık ortalama yağış 1929-2018 y1llar ortalamasına göre $616,7 \mathrm{~mm}$, ortalama sıcaklık $15,1{ }^{\circ} \mathrm{C}$, en yüksek/en düşük sıcaklık ortalamaları ise 19,6/-10,7 ${ }^{\circ} \mathrm{C}$ olmuş, yağışl1 gün sayısı ortalaması 84 olmuştur (Anonim, 2019).

Sulama için çiftlikteki mevcut damla sulama sistemindeki kuyu suyu kullanılmış olup orta kalite sınıfinda bir sulama suyu olduğu $\left(\mathrm{EC}=0,412 \mathrm{dS} \mathrm{m}^{-1}\right)$ Yıldırım ve ark., (2012) tarafindan bildirilmiştir. Sulamalar; her iki dikim şeklindeki bitkilerin solgunluk belirtilerine göre eşit süre ve basınç altında olacak şekilde damla sulama sistemiyle yapılmıştır. Bitkilerin gelişim dönemi boyunca herhangi bir hastalık veya zararlı etkisine rastlanmamış ve herhangi bir pestisit uygulanmamıştır. 
Yabancı ot kontrolü elle ve gerektikçe yapılmıştır. Hasat olgunluğuna ulaşılan domates meyve örnekleri s1k s1k toplanıp etiketlenerek laboratuvara nakledilmiş ve toplam ve tek meyve verimlerinin belirlenmesi için hassas terazide derhal tartımları yapılmıştır. Hasat tamamen bitirildikten sonra, buzdolabında $\left(+4{ }^{\circ} \mathrm{C}^{\prime} \mathrm{de}\right)$ biriktirilen domates meyvelerinin tümünden temsilen ayrilan örneklerde (30 örnek) aşağıda belirtilen kalite analizleri yapılmıştır.

Olgun meyvede renk: Örnekleme yapılarak laboratuvara getirilen her parselden ayrilan meyvelerde $(3 \times 10=30$ adet $)$ Minolta CR-400 renkölçerle $L^{*} a * b$ olarak ölçülmüş ve daha sonra Hue açıs1 ve Chroma olarak hesaplanarak ifade edilmiştir (McGuire, 1992).

Meyve çapı ve meyve boyu $(\mathbf{m m})$ : Her parselden tesadüfen seçilen meyvelerde ( $3 \times 10=30 \mathrm{adet})$ dijital kumpas ile elle meyvenin en geniş ve dar yerlerinden $90^{\circ}$ 'lik açıyla doğrudan ölçülerek aritmetik ortalamaları alınmıştır (Vural ve ark., 2000; Günay, 2005)

Toplam suda çözünebilir kuru madde yüzdesi (\%): Ayrılan örneklerin taze sıkımlarından elde edilen domates suyunda dijital refraktometre (Atago PAL-1 Tokyo-Japonya) yardımı ile doğrudan $20^{\circ} \mathrm{C}^{\prime}$ de ölçülerek belirlenmiştir (Cemeroğlu, 2007).

Titre edilebilir toplam asitlik yüzdesi (\%): Meyve suyundan alınan $5 \mathrm{ml}$ örneğe $10 \mathrm{ml}$ saf su konularak, $0.1 \mathrm{~N} \mathrm{NaOH}$ çözeltisi ile $\mathrm{pH}$ değeri 8.10 değeri elde edilinceye kadar $\mathrm{pH}$ metre ile ölçüm altında titrasyon yapılmıştır. Titre edilebilir asit miktarı, harcanan $\mathrm{NaOH}$ miktarı üzerinden $\mathrm{A}=$ [(S.N.F/C)]x100 förmülüne göre hesaplanarak strik asit cinsinden verilmiştir (Anonim, 1968; Karaçalı, 2009).

L-askorbik asit cinsinden C vitamini miktarı (mg/100g): C vitamin analizleri için örneklerden temsilen seçilen meyvelerin suyundan alınan 5 ml'lik bir kısım metafosforik asitte satabilize edilerek analize hazır hale getirilmiştir. Bu örnekler daha sonra Klejdus ark. (2004)'nın belirttikleri gibi \% 0,010 TFA (Triflorasetikasit) ile Metanol (95:5) karışımından elde edilmiş solüsyonla homojenize edilmiştir. Daha sonra karışım santrifujlenmiş ve üst fazdan alınan sıvı şırınga filitresinden geçirilerek HPLC viallerine verilerek analiz edilmiştir. Ölçümler Shimadzu marka HPLC ile diode array dedektör (DAD) ile yapılmıştır. Örneklerdeki vitamin C miktarını kıyaslamak için önceden altı noktalı kalibrasyon eğrisi (standart seri) hazırlanmış ve ölçümler kalibrasyon sonrası yapılmıştır. HPLC yürütücü faz için pH'1 2.6'ya ayarlanmış $\mathrm{NaH}_{2} \mathrm{PO}_{4}$ ve metanol kullanılmış, akış hızı $0.8 \mathrm{ml} \mathrm{dak}{ }^{-1}$ olarak uygulanmıştır. Cihazda vitamin $\mathrm{C}$ ayırımı için $250 \mathrm{~mm}$ uzunluğunda, $4.6 \mathrm{~mm}$ çapında C18 kolon kullanılmıştır (Heudi ve ark., 2005).

İstatistik analizler: Bölünmüş parseller deneme desenine göre üçer tekrarlı olarak oluşturulan parsellerden elde edilen verilerin SPSS (V. 15.0) paket programında varyans analizleri yapıldıktan sonra "Duncan" çoklu karşılaştırma testi ile önemlilik dereceleri belirlenmiştir.

\section{Bulgular ve Tartışma}

Elde edilen sonuçlara göre, tek meyve ağırlıkları dikim şeklinden istatistiki olarak etkilenmiştir. Standart dikim şeklinden elde edilen meyvelerin ağılıkları AO dikim şekline göre daha yüksek değerler verirken, mikoriza faktörünün meyve ağırlıkları üzerine etkisi istatistiki olarak önemsiz bulunmuştur. Meyve ağırlıklarındaki değişim dikim şekline göre SD lehine meyve boyutlarında da görülmüştür. Standart dikim şeklindeki meyvelerin boyu ve eni AO dikim şekline göre daha yüksek sonuçlar verirken; mikoriza uygulaması meyve boyutlarını ve tek meyve ağırlıklarını istatistiksel olarak etkilememiştir (Çizelge 2). Baum ve ark. (2015) yaptıkları derleme çalışmasında onlarca yayını taramışlar ve domatesin de içinde olduğu çoğu sebze bitkisinin mikoriza uygulamaları ile verim ve kalitelerinde artışlar olduğunu bildirmişlerdir. Domateste dikim aralığının bir faktör olmadan mikoriza uygulamaların etkileri konusunda da birçok araştırmaya rastlanmaktadır (Al-Karaki, 2006; Saka, 2012; Baum ve ark., 2015; Bona ve ark., 2017). Bu araştırmalarda genellikle mikoriza uygulamalarının domateste verim ve kalite özelliklerine önemli etkileri olduğu yönündeki bulgulardan söz edilmektedir. $\mathrm{Bu}$ çalışmamızda ise domateste incelenen özelliklerdeki rakamlar arasında varyasyonlar olmasına rağmen mikoriza uygulamasının istatistik olarak bir etkisi görülmemiştir. Çalışmada özellikle SD şeklinden daha fazla tek meyve ağırlığı elde edilmiş bu durum verim değerlerine de yansımıştır.

Domates bitkisinde farklı dikim şekilleri ve mikoriza uygulamalarının etkisinin birlikte incelendiği tartışabileceğimiz bir başka çalışmaya rastlanmamıştır. Ancak, domates bitkisinde dikim mesafesi, verim ve kalite ilişkileri konusunda birçok çalışmaya rastlanmıştır. 
Domateste dikim aralıklarının düşük olması veya çok sık dikim mesafelerinin verim ve kaliteyi olumsuz etkilediğine dair araştırmalar (Ali, 1997; Anonim, 2008; Cetin ve Uygan, 2008; ElHendawy ve ark., 2008; Tabasi ve ark., 2013; Tuan ve Mao, 2015; Mali ve ark., 2016) daha s1k rastlanırken, bu durumun her bitki için geçerli olmadığı bildirilmektedir (Bodunde ve ark., 1996; ElHendawy ve ark., 2008). Benzer çalışmalarda bazı araştırıcılar, bazı bitkilerin alan başına yoğunluklarının artması ile birlikte verimin azaldığını rapor etmişler ve bunun nedeni olarak da; bitkilerin birbirleri ile rekabete girmesini işaret etmişlerdir (Mohamed, 1999; Griesh ve Yakout, 2001). Çalışmamızdan elde edilen sonuçlara göre, AO dikim şeklinde, standart dikim şekline göre dikim aralıkları bitkiden bitkiye değişmekte ve dikim aralıkları helezonik olarak giderek açılmaktadır. $\mathrm{Bu}$ durum ilk bitkilerde alan başına bitki yoğunluğunu artırırken, ilerleyen dikimlerde bitkilerin aralıklarının açılması, yani alan başına düşen bitki yoğunluğunun azalması olarak karşımıza çıkmaktadır. Böylece helezonik dikim şeklinin merkezindeki bitkiler yoğun rekabete maruz kalırken, helezonik yapının sonuna doğru dikilen bitkiler rekabetten uzak kalmakta, hatta standart dikim şekline göre dikim aralıkları daha fazla olmaktadır. Çalışmamızdan elde edilen değerlerdeki değişkenliğin bu nedenle olduğu kanaatindeyiz.

Ulukapı ve ark. (2009), salkım domateste yaptıkları çalışmada, hem verim hem de meyve kalitesi yönünden önerilebilecek terbiye sisteminin atlatma şeklindeki sık dikim uygulaması olduğunu ifade etmişlerdir. Hamid (1985), beş farklı dikim mesafesinde yetiştirdiği domateslerden en fazla verimi en kısa aralık olan 30 x $100 \mathrm{~cm}$ dikim mesafesinde yetiştirdiği bitkilerden almıştır. En düşük verimi ise en fazla dikim mesafesine sahip $(75 \times 100 \mathrm{~cm})$ yetiştirilen bitkilerden elde etmiştir. Özetle nispeten daha seyrek dikilen domateslerde, dekara verimlerin azaldığı bu tür çalışmalarda da görülmektedir. $\mathrm{Bu}$ durumda tek meyve ağırlıklarındaki değişim bitki üzerindeki meyve sayısının artması ve tek meyve ağırlıklarının azalması şeklinde ortaya çıkmıştır.

Verheul (2012)'e göre, bitki yoğunluğunun azalması ile bitkilerin yaprakları tarafindan kesilen ışığın azalması, başka bir deyişle bitkilerin daha fazla 1şık alması sonucu domateste meyve sayısı ve verim artmaktadır. Nitekim AO dikim şeklinde dikim mesafelerinin giderek açılması ve rekabet şartlarınının değişimi, yukarıda belirtiğimiz gibi tek meyve ağırlıklarında ve dolaylı olarak toplam verimde de kararsızlıklara, artış ve azalmalara yol açmıştır. Dikim aralıklarının fazla olması veya çok sık dikim mesafeleri verim ve kaliteyi olumsuz etkilemesinin bir nedeni olarak bitki üzerindeki meyve sayısının artması, ancak tek meyve ağırlıklarının azalması şeklinde de belirtilmiştir (Anonymous, 2008).

AO dikim şeklinde bitkiler arasındaki mesafelerin ilk başlarda kısa ancak daha sonra giderek uzaması ve metrekareye düşen bitki sayısının artması nedeni ile bu durum açıklanabilmektedir. Altın oran dikim şeklinde özellikle helezonik dikimin başlarında birim alana daha fazla bitki dikilmiş olması bu parsellerden elde edilen meyvelerin daha hafif ve küçük boyutlarda olmasının nedeni olabilir. $\mathrm{Bu}$ durumun nedeni olarak bitkiler arasında yaşanması muhtemel su ve gün 1şığı gibi hayati öneme sahip faktörler için girilen rekabetler olabileceği düşünülmektedir. Çünkü domates ve hıyar bitkilerinde dikim sıklıkları ile 1şık kanopisi arasında bir ilişkinin bulunduğu, bitki kanopisine giren ışığın alt yapraklar tarafından kullanılmasının bitki büyüme süresini, fotosentetik kapasiteyi ve dolayısıyla verimi etkileyebildiği; özellikle de sera şartlarında, sera içi oransal nem seviyesi ve bitki kanopisi içerisine yeterli ışığın ulaşıp ulaşamaması durumuna bağlı olarak domates ve hıyar bitkilerinde mantari ve bakteriyel hastalıkların ortaya çıkması verim ve kaliteyi önemli derecede azalttığ1 belirtilmektedir (Saka, 2012). Elde ettiğimiz bulgular Saka (2012) 'nin elde ettiği bulgular ile örtüşmektedir. Çalışmamız elde edilen veriler bu yönüyle daha önce yürütülmüş ve yayınlanmış makalelerdeki sonuçlar ile uyum göstermektedir.

Çizelge 2. Domates meyvelerinde pomolojik özelliklerin değişimi

\begin{tabular}{|l|l|l|l|l|l|l|l|l|l|}
\hline & \multicolumn{3}{|l}{ Tek Meyve Ağırlı̆̆ $(\mathbf{g})$} & \multicolumn{3}{l|}{ Meyve Çapı (mm) } & \multicolumn{2}{l|}{ Meyve Boyu (mm) } \\
\hline Dikim Şekli & M+ & M- & Ortalama & M+ & M- & Ortalama & M+ & M- & Ortalama \\
\hline Standart & 158,00 & 172,00 & $165,00 \mathbf{a}^{*}$ & 65,41 & 68,86 & 67,13 a & 59,61 & 60,16 & 59,88 a \\
\hline Altın Oran & 133,83 & 128,50 & $131,16 \mathbf{b}$ & 61,40 & 62,41 & $61,90 \mathbf{b}$ & 56,20 & 54,74 & $55,47 \mathbf{b}$ \\
\hline Ortalama & 145,91 & 150,25 & & 63,40 & 65,64 & & 57,90 & 57,45 & \\
\hline
\end{tabular}

$\mathrm{M}^{+}$: Mikoriza uygulanan parseller, $\mathrm{M}^{-}$: Mikoriza uygulanmayan parseller, *: Farklı harfler aynı sütunlardaki uygulamalar arası farkları göstermektedir. 
Ölçülen meyve kabuk rengi (Hue ${ }^{\circ}$ ve Chroma) değerleri hem dikim şekli hem de mikoriza uygulamalarından istatistiki olarak etkilenmemiştir. Domates meyvelerinde kalite ve olgunluk ifadelerinde kullanılan bu renk değerleri gerek mikorizadan gerekse dikim şeklinden istatistiksel olarak etkilenmemiştir (Çizelge 3). Domateste meyve kalitesini ve alımını etkileyen en önemli özelliklerden birinin meyve rengi olduğu ve rengin yetiştiricilik, stres koşulları ve genetik özelliklerden etkilenebildiği bilinmektedir (Matas ve ark., 2009). Kroma ya da saturasyon değeri rengin keskinliğini ifade etmektedir. Domates açısından bu değer yükseldikçe kırmızı renk değeri yükselir ancak yoğunluğu düşer. Hue değeri rengin temel bileşenlerini belirlemektedir (McGuire, 1992).

Sonuçlar irdelendiğinde standart dikim şeklinde hue açısı ve kroma değerlerinin daha yüksek olduğu görülmektedir. Özetle rengin matlık değerini gösteren kroma değeri yükseldikçe kırmızı rengin parlaklığı artmaktadır. Bu durumda standart dikim şeklinde meyve renginin daha parlak olduğu söylenebilir. Bu durum istatistiki olarak önemli bulunmasa da araştırıcılar dikim aralıklarından rengin etkilendiğini düşünmektedirler. Bunun nedeni hem rekabet koşulları hem de dikim aralıklarının AO dikiminde giderek artmasına bağlanabilir. Verheul (2012)'e göre, bitki yoğunluğunun azalması ile bitkilerin yaprakları tarafından kesilen 1şığın azalması, başka bir deyişle bitkilerin daha fazla 1 şı alması sonucu domateste meyve sayısı ve verim artmaktadır. Işık ile domates renginin olgunlaşma aşamasının birbiri ile ilişkili olduğu göz önüne alındığında AO dikim şeklindeki renk olumsuzlukları ya da kararsızlıkları açıklanabilir.

Çizelge 3. Domateste meyve rengi ve içsel kalite özelliklerinin değişimi

\begin{tabular}{|l|l|l|l|l|l|l|l|l|l|l|}
\hline & \multicolumn{3}{|c|}{ Chroma } & \multicolumn{3}{c|}{ Hue $^{\circ}$} & \multicolumn{3}{c|}{ TSÇKM (\%) } \\
\hline Dikim Şekli & M+ & M- & Ortalama & M+ & M- & Ortalama & M+ & M- & Ortalama \\
\hline Standart & 49,55 & 49,50 & 49,53 & 57,73 & 56,33 & 57,03 & 4,33 & 4,50 & 4,41 \\
\hline Altın Oran & 47,02 & 48,79 & 47,91 & 58,14 & 57,34 & 57,74 & 4,36 & 4,56 & 4,46 \\
\hline Ortalama & 48,29 & 49,15 & & 57,94 & 56,84 & & 4,35 & 4,53 & \\
\hline
\end{tabular}

TSÇKM: Toplam suda çözünebilir kuru madde, $\mathrm{M}^{+}$: Mikoriza uygulanan parseller, $\mathrm{M}^{-}$: Mikoriza uygulanmayan parseller

Vitamin $\mathrm{C}$ bakımından ise mikoriza uygulamasının her iki ekim şeklinde de bir etkisi görülmemişken SD şekliyle elde edilen ürünlerde C vitamini daha fazla $(p<0,05)$ olmuştur (Çizelge 34). Vitamin $C$ ile ilgili sebzelerde özellikle azotlu gübreler başta olmak üzere gübre uygulamalarının olumsuz etkisi olabildiği belirtilmektedir (Lisiewska ve Kmiecik, 1996). Bu çalışmada organik veya inorganik herhangi bir gübreleme yapılmamış olması $\mathrm{C}$ vitamini değerlerini etkilememiş olabilir ancak sık ekim durumunda kalan AO dikim şeklindeki bitkilerin kök gelişimine etkisi olabilir. Bu konudaki Thybo ve ark. (2006)'nın domatesle ilgili yaptıkları çalışmada; kökleri serbest, yarı kısıtlı ve tam kısıtlı olan bitkilerde $\mathrm{C}$ vitamini analizleri yapmışlar ve 11,8-16,6 mg/100g C vitamini değerlerini elde etmişlerdir. $\mathrm{Bu}$ değerler çalışmamızda elde edilen vitamin $\mathrm{C}$ değerleri ile uyumludur, ancak araştırmacılar kısıtlı kök durumunda olan domateslerde erken hasatta daha fazla vitamin $\mathrm{C}$ değeri elde ettiklerini de belirtmişlerdir.

Domateste kalite parametrelerinden SÇKM ve TETA miktarlarını ne dikim şekli ne de mikoriza uygulamaları bu çalışmada istatistiki olarak etkilememiştir (Çizelge 4). Ancak, AO dikim şeklinde ortalama olarak SÇKM'nin yüksek olduğu söylenebilir. Bu durum, AO dikim şeklindeki domateslerden nispeten daha küçük meyveler elde edilmesi ile açıklanabilir.

Bona ve ark., (2017) yaptıkları çalışmada özellikle domates bitkilerine uyguladıkları vesiküler arbusküler mikorhiza (VAM)'nın en önemli etkisini; domateslerde sitrik asit konsantrasyonlarını iyileştirmesi şeklinde belirtmektedirler. Pseudomonas $19 \mathrm{Fv} 1 \mathrm{~T}$ bakterisinin ise şeker üretimi ve domates tatlılı̆̆ını olumlu bir şekilde etki ettiğini belirtmektedirler. Ancak çalışmamızda TETA yüzdesi bakımından istatistiki fark oluşmamıştır. Bu durum tartışmaya açıktır. Diğer sonuçlarda da mikoriza uygulamasının sınırlı veya farksız etkisi olduğu göz önüne alındığında, çalışmada uygulanan mikorizanın uygulama yöntemi açısından sorunlar olabileceği de düşünülebilir. 
Çizelge 4. Domateste C vitamini içerikleri ve TETA değerlerindeki değişimler

\begin{tabular}{|l|l|l|l|l|l|l|}
\hline & \multicolumn{3}{|c}{ C Vitamini (mg 100 $\left.\mathbf{g}^{-1}\right)$} & \multicolumn{4}{c|}{ TETA (\%) } \\
\hline Dikim Şekli & $\mathbf{M}^{+}$ & $\mathbf{M}^{-}$ & Ortalama & $\mathbf{M}^{+}$ & $\mathbf{M}^{-}$ & Ortalama \\
\hline Standart & 14,37 & 14,36 & $14,37 \mathbf{a}^{*}$ & 0,412 & 0,416 & 0,414 \\
\hline Altın Oran & 12,69 & 12,60 & $12,65 \mathbf{b}$ & 0,409 & 0,428 & 0,419 \\
\hline Ortalama & 13,53 & 13,48 & & 0,411 & 0,423 & \\
\hline
\end{tabular}

TETA: Titre edilebilir toplam asitlik (sitrik asit), $\mathrm{M}^{+}$: Mikoriza uygulanan parseller, $\mathrm{M}^{-}$: Mikoriza uygulanmayan parseller,

*: Farklı harfler aynı sütunlardaki uygulamalar arası farkları göstermektedir.

\section{Sonuç}

Sonuç olarak mikoriza uygulamaları her iki dikim şeklinde domates verimi ve kalitesine etki etmemiş; SD şekline göre AO dikim şekli domatesin verim ve kalitesi yönünden beklenen başarıyı gösterememiştir. Altın oran dikim şeklinde özellikle küçük parsel boyutlarında domates bitkileri arasındaki mesafelerin yetersiz olacağı sonucuna varılmıştır. Altın oranın uygulanacağı büyük parsellerde helezonik sarmallar genişleyip yayılacağı düşünüldüğünde durumum değişebileceği düşünülmektedir.

Araştırmacılara bu konuda tarla şartlarında mikorizalı veya mikorizasız başka bitkiler ve başka parsel boyutlarında denemeler yapmaları önerilebileceği gibi, ayni bitkide farklı parsel boyutlarını çalışmaları da önerilebilir. Hatta her iki dikim şeklindeki bitki sayısının eşitlendiği farklı parsel boyutları farklı bitkiler için ele alınabilir.

\section{Kaynaklar}

Agele, S.O., Iremiren, G.O., Ojeniyi, S.O., 1999. Effects of plant density and mulching on the performance of late-season tomato (Lycopersicon esculentum) in southern Nigeria. The Journal of Agricultural Science, 133(4): 397-402.

Akhtaruzzaman, M., Shafie, A.A., 2011. Geometrical substantiation of Phi, the golden ratio and the baroque of nature, architecture, design and engineering. International Journal of Arts, 1(1): 1-22.

Alexopouluos, J.C., 1962. Introductory Mycology. John Wiley \& Sons Inc. New York, 613p.

Ali, S.M.R., 1997. Effect of plant population density on tomato. ARC Training Report, pp 1-3.

Al-Karaki, G.N., 2006. Nursery inoculation of tomato with arbuscular mycorrhizal fungi and subsequent performance under irrigation with saline water. Scientia Horticulturae 109, 1-7.

Anonim, 1968. Analyses. Determination of titrable acid. International federation of fruit juice producers. No:3.

Anonim, 2008. Commercial Greenhouse Tomato Production: Tomato Plant Propagation. www.agric.gov.ab.ca/\$department/deptdocs.nsf/all/opp7957

Anonim, 2016. https://www.blender.org/about/ erişim tarihi; 03.04.2016.

Anonim, 2017a. FAO istatistikleri, www.fao.org/statistics. Erişim tarihi: 25.04.2019.

Anonim, 2017b. Tarım Gida ve Hayvancilık Bakanlığı İstatistikleri, https://canakkale.tarim.gov.tr/Menu/13/Brifingler. Erişim tarihi: 12.02.2018.

Anonim, 2018. FAO (Food and Agriculture Organization) of the United Nations statistics division website. Available on: http://www.fao.org/faostat/en/\#data/QC/visualize.

Anonim, 2019. T.C. Tarım ve Orman Bakanlığı, Meteoroloji Genel Müdürlüğü, https://www.mgm.gov.tr/veridegerlendirme/il-ve-ilceleristatistik.aspx?k=undefined\&m=CANAKKALE. Erişim Tarihi; 25.09.2019.

Baum, C., El-Tohamy, W., Gruda, N., 2015. Increasing the productivity and product quality of vegetable crops using arbuscular mycorrhizal fungi: A review. Scientia Horticulturae, 187, 131-141.

Bejan, A., 2009. Int. J. of Design \& Nature and Ecodynamics. Vol. 4, No. 2.

Bodunde, J.G., Erinle, I.D., Eruotor, P.G., 1996. Selecting tomato genotypes for heat tolerance using Fasoulas' line method. Proceeding of 14 HORTON conference. Ago-Iwoye, 1(4): 24-34.

Bona, E., Cantamessa, S., Massa, N., Manassero, P., Marsano, F., Copetta, A., Berta, G., 2017. Arbuscular mycorrhizal fungi and plant growth-promoting pseudomonads improve yield, quality and nutritional value of tomato: a field study. Mycorrhiza, 27(1): 1-11.

Cemeroğlu, B., 2007. Gıda Analizleri. Gıda Teknolojisi Derneği Yayınları No:34. Bizim Büro Basımevi, 535 s., Ankara.

Cetin, O., Uygan, D., 2008. The effect of drip line spacing, irrigation regimes and planting geometries of tomato on yield, irrigation water use efficiency and net return, Agricultural Water Management, 95: 949-58. 
Dumas, Y., Dadomo, M., Di-Lucca, G., Grolier, P., 2003. Effects of environmental factors and agricultural techniques on antioxidantcontent of tomatoes. Journal of the Science of Food and Agriculture, 83(5): 369-382.

El-Hendawy, S.E., El-Lattief, E.A., Ahmed, M.S., Schmidhalter, U., 2008. Irrigation rate and plant density effects on yield and water use efficiency of drip-irrigated corn. Agricultural Water Management 95: $836-44$

Foolad, M.R., 2007. Genome mapping and molecular breeding of tomato. Int. J. of Plant Gen. vol. 2007, Article ID 64358, 52 pages.

Giovannetti, M., Avio, L., Barale, R., Ceccarelli, N., Cristofani, R., Iezzi, A., Mignolli, F., Picciarelli, P., Pinto, B., Reali, D., Sbrana, C., Scarpato, R., 2012. Nutraceutical value and safety of tomato fruits produced by mycorrhizal plants. Br. J. Nutr. 107:242-251.

Griesh, M.H., Yakout, G.M., 2001. Effect of plant population density and nitrogen fertilization on yield and yield components of some white and yellow maize hybrids under drip irrigation system in sandy soil. (In) Proceedings of the International Conference on Plant Nutrition-Food Security and Sustainability of Agro-ecosystems, Madrid, Spain, pp 810-1.

Günay, A., 2005. Sebze Yetiştiriciliği. Cilt 1.İzmir.

Hamid, M., 1985. Effect of Plant Density on Tomato Yield. www.arc-avrdc.org/pdf_files/ Monjurhamid(3N).pdf

Hanareh, M., Dursun, A., Mandoulakani, B.A., 2015. Genetic diversity in tomato landraces collected from Turkey and Iran revealed by morphological characters. Acta Sci. Pol. Hortorum Cultus, 14(2): 87-96.

Heudi, O., Kilinc, T., , Fontannaz, P., 2005. Separation of water-soluble vitamins by reversed-phase high performance liquid chromatography with ultra-violet detection: Application to polyvitaminated premixes, Journal of Chromatography A, 1070, 49-56.

Kara, Ö., Tilki, F., 2001. Mikoriza ve Ormancılıkta Kullanımı. İ.Ü Orman Fakültesi Dergisi. B51 Sayı: 1.

Karaçalı, İ., 2009. Bahçe Ürünlerinin Muhafaza ve Pazarlanması. Ege Üniversitesi Ziraat Fakültesi Yayınları, No: 494, Bornova/IZZMIR.

Klejdus, B., Petrlová, J., Potěšil, D., Adam, V., Mikelová, R., Vacek, J., Kubáň, V., 2004. Simultaneous determination of water-and fat-soluble vitamins in pharmaceutical preparations by high-performance liquid chromatography coupled with diode array detection. Analytica Chimica Acta, 520(1): 57-67.

Lisiewska, Z., Kmiecik, W., 1996. Effects of level of nitrogen fertilizer, processing conditions and period of storage of frozen broccoli and cauliflower on vitamin C retention. Food Chemistry. 57(2): 261-270.

Matas, A.J., Gapper, N.E., Chung,Mi-Y., Giovannoni, J.J., Rose, J.K.C., 2009. Biology andgenetic engineering of fruitmaturation for enhanced quality and shelf-life. Curr.Opin. Biotechnol., 20, 197-203.

Mali, S.S., Jha, B.K., Naik, S.K., Singh, A.K., Kumar, A., 2016. Effect of fertigation pattern and planting geometry on growth, yield and water productivity of tomato (Solanum lycopersicum). Indian Journal of Agricultural Sciences, 86(9): 1208-13.

McGuire, G.R., 1992. Reporting of objective color measurements. HortScience, 27(12): 1254-1255.

Mohamed, M.M.A., 1999. 'Effect of some agronomic practices on corn production (Zea mays L.) under drip irrigation system'. Ph D thesis, Faculty of Agriculture, Suez Canal University, Ismailia, Egypt, p107.

Murchie, G., 1999. The seven mysteries of life: an exploration in science \& philosophy. Houghton Mifflin Harcourt.

Ortas, İ., Sari, N., Akpinar, Ç., Yetişir, H., 2011. Screening mycorrhiza species for plant growth, P and Zn uptake in pepper seedling grown under greenhouse conditions. Scientia Horticulturae, 128(2): 92-98.

Ortaş, İ., 1997. Mikoriza nedir? TÜBİTAK Bilim ve Teknik Dergisi, 351: 92-95.

Ortaş, İ., 2010. Effect of mycorrhiza application on plant growth and nutrient uptake in cucumber production under field conditions. Spanish J. Agr. Res. 8(S1):116-122.

Özcan, H., Ekinci, H., Yüksel, O., Kavdır, Y., Kaptan, H., 2004. Çanakkale Onsekiz Mart Üniversitesi Ziraat Fakültesi Dardanos Yerleşkesi Toprakları. Çanakkale Onsekiz Mart Üniversitesi Yayın No: 39. Çanakkale.

Papadopoulos, A.P., Ormrod, D.P., 1991. Plant spacing effects on growth and development of the greenhouse tomato. Can. J. Plant Sci. 71: 297-304.

Parlak, M., Türkmen, C., Parlak, A.Ö., Akçura, M., Özkan, N., 2017. Effects of Some Legumes on Physical and Biological Soil Characteristics. In: 2nd International Balkan Agriculture Congress 16-18 May, Congress Book; 914-919.

Plenchette, C., Clermont-Dauphin, C., Meynard, J.M., Fortin, J.A., 2005. Managing arbuscular mycorrhizal fungi in cropping systems. Canadian J. Plant Sci. 85(1): 31-40.

Prokopakis, E.P., Vlastos, I.M., Picavet, V.A., Nolst, T.G., Thomas, R., Cingi, C., Hellings, P.W., 2013. The golden ratio in facial symmetry. Rhinology, 51(1): 18-21. 
Saka, A.K., 2012. Serada İlk Turfanda Organik Domates (Solanum lycopersicum L.) ve Hiyar (Cucumis sativus L.) Yetiştiriciliğinde Farklı Dikim Sistemleri ve Mesafelerinin Büyüme, Gelişme, Verim ve Kaliteye Etkileri. Ondokuz Mayıs Üniversitesi Fen Bilimleri Enstitüsü, (Basılmamış) Yüksek Lisans Tezi, 70s.

Selçuk, S.A., Sorguç, A.G., Akan, A.E., 2009. Altın Oranla Tasarlamak: Doğada, Mimarlikta Ve Yapisal Tasarimda $\Phi$ Dizini. Trakya Univ. J. Sci, 10(2):149-157, 2009.

Tabasi, A., Nemati, H., Akbari, M., 2013. The effects of planting distances and different stages of maturity on the quality of thee cultivars of tomatoes (Lycopersicon esculentum Mill). Notulae Scientia Biologicae, 5(3): 371-5.

Thybo, A.K., Edelenbos, M., Christensen, L. P., Sørensen, J. N., Thorup-Kristensen, K., 2006. Effect of organic growing systems on sensory quality and chemical composition of tomatoes. LWT-Food Science and Technology, 39(8): 835-843.

Tuan, N.M., Mao, N.T., 2015. Effect of plant density on growth and yield of tomato (Solanum lycopersicum L.) at Thai Nguyen, Vietnam. International Journal of Plant and Soil Science 7(6): 357-61.

Türkeş, M., Savaş, T., Baytekin, H., Uğur, K., 2011. Çanakkale' de olası iklim değişmeleri ve tarımsal üretime etkileri. Çanakkale Tarım Sempozyumu (Dünü, Bugünü ve Geleceği) 10-11 Ocak 2011, s. 257-270. Çanakkale.

Uluer, K., Karabulut, S., 1999. Mikoriza ve Ormancılıktaki Yeri. Kavak ve Hızlı Gelişen Orman Ağaçları Araştırma Müdürlüğü. Seri No:26, İzmit.

Ulukapı, K., Ercan, N., Onus, A.N., 2009. Farklı Terbiye Şekillerinin ve Dikim Mesafelerinin M19 Salkım Domates Çeşidinde Verim ve Kalite Üzerine Etkileri. Akdeniz Üniversitesi Ziraat Fakültesi Dergisi, 22(2): 233-238.

Verheul, M.J., 2012. Effects of plant density, leaf removal and light intensity on tomato quality and yield. In: VII International Symposium on Light in Horticultural Systems 956, 365-372.

Vural, H., Eşiyok, D., Duman, İ., 2000. Kültür Sebzeleri (Sebze Yetiştirme). Ege Üniversitesi Basım Evi, Bornova, Izmir.

Wang, B., Qiu, Y.L., 2006. Phylogenetic distribution and evolution of mycorrhizas in land plants. Mycorrhiza 16: 299-363.

Y1ldırım, M., Bahar, E., 2017. Water and radiation use-efficiencies of tomato (Lycopersicum esculentum L.) at three different planting densities in open field. Mediterranean Agricultural Sciences, 30(1): 39-45.

Yıldırım, M., Demirel, K., Bahar, E., 2012. Effect of restricted water supply and stress development on growth of bell pepper (Capsicum annuum L.) under drought conditions. Journal of Agro Crop Science, 3(1): 19 . 